Journal of Universal Language 6

March 2005, 29-63

\title{
Entailment-based Linking Theory and Some Implications for Universal Language
}

\author{
Luis González \\ Wake Forest University
}

\begin{abstract}
This article shows that Dowty (1991)'s proto-agent and protopatient set of entailments can be reduced to two discrete entailments: an unergative entailment and an unaccusative entailment. The former is an adaptation of -er noun formation in the sense that not all -er nouns in English refer to subjects, but all subjects of (di)transitive predicates and a subset of intransitive ones (the unergatives) allower noun formation. The latter entailment was proposed as a participle-adjective conversion rule by Bresnan (1982). Using these two entailments as tests for unaccusativity and unergativity, this article shows a more restrictive and predictive linking theory than Dowty (1991) and Wechsler (1995). Many verbs listed by them as exceptions (lexical doublets, nonstandard lexicalizations, syncategorematic verbs) are accounted for with the same Verber/Verbed Argument Selection Principle that accounts for Dowty's principle and for Wechsler's three linking rules.
\end{abstract}

Keywords: argument selection principle, linking, macro-roles, proto-roles, Unaccusative Hypothesis 
30 Entailment-based Linking Theory and Some Implications for

Since the first Greek and Latin grammars, dating back approximately twenty centuries, linguistic theory has been based on grammatical case, with nominative as the technical term for subject, accusative for direct object, and dative for indirect object.

Linguistic theory based on case was formally challenged in 1965, when Jeffrey Gruber (published as Gruber 1976) proposed that grammatical relations (subject, direct object, indirect object) could not express many generalizations that were better accounted for using semantic counterparts of grammatical relations. He proposed, instead, that terms like agent, theme, location, goal, and source, which he called thematic roles, should be posited as part of linguistic theory. The linguistic community immediately embraced these terms, although they have been the subject of much debate during the last four decades.

\section{Who does What to Whom?}

Theta role theory is the part of linguistic theory that deals with who does what to whom or to what in a sentence (Carlson 1984). Linking theory addresses the assignment of thematic roles (agent, theme, patient, goal, experiencer) to grammatical relations (subject, direct object, indirect object). From childhood, speakers of all languages - without having heard the terms subject, direct object, experiencer, locative, and so on-can assign thematic roles to grammatical relations very efficiently, yet analyzing how we do so has been one of the most controversial tasks for linguistics, as the following statement from Dowty (1991:547) shows:

There is perhaps no concept in modern syntactic and semantic theory which is so often involved in so wide a range of contexts, but on which there is so little agreement as to its nature and 
definition, as THEMATIC ROLE (or THEMATIC RELATION) and its derivative, THETA-ROLE in Government-Binding (GB) theory.

The enterprise of defining discrete thematic roles (actor, agent, effector, patient, theme, instrument, goal, benefactor, undergoer, source, experiencer, location) has proven extremely problematic, and it has been largely abandoned in its original form. Instead, over half a dozen more encompassing proposals have been advanced.

This article presents a new theory of linking, compares it with two well-known linking theories, and shows how it solves several long-standing problems for linking theory. First, it proposes a solution for the misalignment in grammatical relations and theta roles in pairs like fear and frighten in English. A similar problem, involving animacy hierarchy misalignment and accusative/dative alternations is attested in many other languages. This phenomenon is known as psych(ological) predicates. Second, it offers a simpler way (using two discrete entailments) to test unaccusativity.

\section{The Unaccusative Hypothesis}

I will argue that a formulation of the Unaccusative Hypothesis (hereafter UH) in terms of thematic roles instead of grammatical relations captures the best intuitions behind the main theories of linking and avoids many of their pitfalls. I will briefly state the main idea behind the $\mathrm{UH}$, formulate it in terms of thematic roles, and compare this new proposal with two theories of linking: 1) Dowty's protoroles, and 2) Wechsler's three linking rules. The comparison will show that the present proposal is more restrictive and predictive 
32 Entailment-based Linking Theory and Some Implications for

than previous linking theories. ${ }^{1}$

First proposed by Barbara Hall-Partee in her dissertation (1965), the UH is widely known after work by David Perlmutter (1978) and subsequent work in Relational Grammar (hereafter RG). The main idea behind unaccusativity is that the subject of a subset of intransitive verbs is an underlying direct object. In RG's terms, the 1 of unaccusative predicates is an initial 2 that is promoted to final 1 .

The UH is one of the few concepts in linguistics shared by virtually all mainstream theories. Dowty shows some skepticism about unaccusativity as a syntactic phenomenon, presumably because it entails different strata and the need for derivations (609ff). More work on unaccusativity and the development of more lexicalists theories have made it possible to adopt unaccusativity without committing to derivations or transformations. In HeadDriven Phrase Structure Grammar (HPSG), and in Relational Grammar (RG), Arc Pair Grammar, Lexical Functional Grammar (LFG), Generalized Phrase Structure Grammar (GPSG), and Categorical Grammar, among others (Pollard \& Sag 1994:119), passive is a lexical rule:

Passive is an operation on grammatical relations, one that 'demotes' subject arguments (universally, including impersonal passivization in many languages) and, in many instances, additionally 'promotes' more oblique syntactic dependents (e.g., primary objects in English, or perhaps primary and secondary objects in other languages to subject status). This relational

\footnotetext{
1 These two linking theories are representative for two reasons. Dowty's theory is perhaps the most widely used linking theory, as attested by constant references to his incremental theme. Wechsler's theory is representative of other attempts at formulating a linking theory, since his three rules have precedents either in linguistics or in philosophy. Van Valin \& LaPolla (1997) and Davis (2001) are two other influential linking theories. A comparison of my theory with those of Davis (2001) and Van Valin \& LaPolla is under review.
} 
characterization of passivization represents a significant point of agreement among many researchers working in diverse theoretical frameworks.

For Van Valin \& LaPolla (1997:147), who propose another nontransformational model, "passive is a syntactic valence-changing rule because in sentences like John was killed and The sandwich was eaten the syntactic valence of the verb is reduced from two to one."

Many have proposed tests to determine whether a verb is unaccusative or unergative (see Rosen 1988, Rappaport \& B. Levin 1988, Legendre 1989, Farrell 1994, Levin \& Hovav 1999, among others). Legendre (1989) discusses a battery of tests for unaccusativity. Any verb that can pass at least one of her nine tests is unaccusative, and all others are unergative. Rather than discussing all of her tests (and some of the other tests proposed), I will concentrate on two of the more commonly used that show the most relevant distinction.

Before proceeding with the discussion, a cautionary note: I will not refer to unergative or accusative verbs but to unergative or unaccusative (or unaccusativized) predicates. The reasons are simple. First, the same verb can appear in a transitive as well as a detransitivized predicate, maintaining its meaning throughout. Consider this example from Rosen (1988:52):

(1) a. Ugo ha continuato la lotta.

'Ugo has continued the struggle.'

b. Ugo ha continuato.

'Ugo has continued.'

c. La lotta è continuata.

'The struggle has continued.'

Is continue transitive or intransitive? Probably both or probably 
34 Entailment-based Linking Theory and Some Implications for

neither, for it is the (in)transitivity of the predicate that is relevant. The predicate in (1a) is transitive, but the predicates in both (1b) and (1c) are intransitive. As will be shown below, they are detransitivized: (1b) is an unergative predicate, and (1c) is an unaccusative one or, better yet, an unaccusativized one. Consider also sentences like The children ate soup vs. The children ate and The heat melted the ice vs. The ice melted. The verbs are the same, but the predicates are transitive or detransitivized. Second and more important, the task of the speaker or listener is figuring out the linking of a given predicate, not a verb, as this article will show.

\section{The Unaccusative and the Unergative Tests}

All the tests proposed so far for unaccusativity can be subsumed by the unergative test (Farrell 1994:139, Rappaport \& Levin 1988) and the Participle-Adjective Conversion Rule of Bresnan (1982:2331). The unergative test provides evidence that subjects of ditransitive, monotransitive, and intransitive verbs are initial $1 \mathrm{~s}$ in $\mathrm{RG}$ or the external argument of GB, if the referent of the subject can be affixed with -er. I have adapted this test with what I call the verber paraphrase, since it allows the paraphrase " $\underline{x}$ is the verber," with $\underline{x}$ being the argument whose role is at issue. If such a paraphrase is entailed by the original predicate, and if it is semantically sound, the $\underline{x}$ argument is an initial 1 or the external argument. On the other hand, Bresnan's Participle-Adjective Conversion Rule provides evidence that an $\underline{\mathrm{x}}$ argument is an object or theme (an initial 2 in RG or an internal direct argument), if the paraphrase "the verbed $\underline{x}$ " is entailed by the original predicate, and it is semantically sound. Consider the transitive predicate in (2):

(2) a. Margarita returned the blouse. 

b. Margarita is the returner.
c. \#The returned Margarita. ${ }^{2}$
d. \#The blouse is the returner.
e. The returned blouse.

The fact that the string in (2b) is entailed by (2a) tells us that Margarita is an initial 1 or an external argument or, in terms of the original discrete roles, an agent. We will refer to strings like those in (2b) as the UNERGATIVE ENTAILMENT, meaning that this string shows that the argument at issue (the subject, in this case) passes the unergative test. For reasons that will become clear as more examples are discussed, we will refer to an argument that satisfies the unergative entailment as the VERBER. The fact that the string in (2e) is also entailed by (2a) tells us that the blouse is an initial 2 or an internal direct argument or, in terms of the old discrete roles, a patient or theme. We will refer to strings like those in (2e) as the ACCUSATIVE ENTAILMENT, meaning that the argument at issue passes the accusative test. When the accusative entailment refers to an accusative argument in subject position, we will refer to it as the unaccusative entailment. This distinction captures the difference between an accusative-marked participant in its default direct object position and its ability to show up in subject position, when the predicate is unaccusative or unaccusativized. For reasons that will become clear soon, we will refer to an argument that satisfies the accusative entailment as the VERBED. Observe that the returned Margarita could be a semantically sound string but as an entailment from a predicate like Margarita returned to town. However, it is not entailed by Margarita returned the blouse, because in this predicate she is the returner, not the returned.

\footnotetext{
2 The notation \# indicates that the string is semantically or pragmatically anomalous (\#We frightened the cheese). Both the definition and the example come from Huddleston \& Pullum (2002:xii).
} 
36 Entailment-based Linking Theory and Some Implications for

The unergative test, as formulated above, is entailment-based; that is, Margarita returned the blouse entails that Margarita is the returner. The Participle-Adjective Conversion Rule is also entailmentbased, as (2) and (4) show. Ladusaw \& Dowty (1988) showed that entailments and presuppositions prevail, when they have to compete with roles in deciding controllers in control predicates. Thus, unergative and accusative paraphrases, as used in this article, are entailments derived from a corresponding proposition. Dowty's protoroles are also entailment-based since the choice of protorole depends on the number of protorole entailments that each argument of a verb satisfies. Davis's protorole attributes also refer to sets of entailments that an argument will satisfy (2001). As shown above, the unergative and the accusative entailments need not be a set, as they are in Dowty and in Davis (2001); in the present theory, there is simply the unergative entailment and the accusative entailment. Dealing with two discrete entailments instead of two sets of entailments is already a simplification in a theory of linking, because instead of computing the number of entailments from a given set satisfied by an argument, we simply verify which of only two possible entailments an argument satisfies.

The unergative entailment and the unaccusative entailment also give correct results when applied to intransitive (3) or detransitivized (4) predicates:

(3) a. Rose works.

b. Rose is the worker.

c. \#The worked Rose.

(4) a. The flowers wilted.

b. \#The flowers are the wilter.

c. The wilted flowers. 
Notice that (3b) is semantically sound and entailed by (3a). Furthermore, nobody disputes the existence of the noun worker. As for (3c), no native speaker would say "the worked Rose." The unergative entailment shows that Rose is the VERBER in (3a). In (4b), the string "the flowers are the wilter" is not entailed by (4a), but the string "the wilted flowers" is. The grammatically, semantic soundness, and interpretability of (4c) indicate that the flowers are the VERBED. "The flowers wilted" is an unaccusative or, better yet, an unaccusativized predicate, and the accusative entailment shows a subject that is not a VERBER but a VERBED.

As this article will show, all VERBERS are subjects, but not all subjects are VERBERS, and the roles VERBER and VERBED, for which we will be arguing in this article, do not always coincide with subject and direct object, respectively, in the same way that the macroroles ACTOR and UNDERGOER do not necessarily coincide with subject and object, "because either the ACTOR or the UNDERGOER can be subject in English" (Van Valin \& LaPolla [142]). The same goes for subjects, that are VERBEDS, of predicates like The ice melted (from The heat melted the ice), The river froze (from $A$ drop in temperature froze the river), Taxes increased (from The government increased taxes), and, of course, the truly unaccusative The mail arrived (cf., the newly arrived mail has not been processed vs. \#the mail is the arriver). Thus, the VERBER/ VERBED distinction brings out a difference in the role of the subject that the nominative has blurred for centuries. This distinction was brought to the linguistic community's attention by Barbara HallPartee and David Perlmutter and is restated in this article in terms of thematic roles rather than grammatical relations or the terms 1,2 , and 3 of RG. 
38 Entailment-based Linking Theory and Some Implications for

\section{The Unaccusative Hypothesis and Thematic Roles}

Farrell (1994) proposed to add thematic roles to RG, but the idea does not seem to have taken off, despite the fact that the UH is perhaps the only module of syntactic theory shared by virtually all syntactic frameworks. This article will show that the unergative and accusative tests can be formulated as entailments that amount to two thematic roles, the VERBER and the VERBED. The distinction of VERBER and VERBED constitutes a more constrained and predictive linking theory than mainstream linking theories, while capturing their best insights.

If we were to formulate the UH in terms of the VERBER and VERBED distinction, as brought out by the unergative and the (un)accusative entailments, we get the following:

There are two classes of intransitive predicates. For one of them, the subject is the VERBER, because it satisfies better the unergative entailment than the unaccusative entailment. For the other, the subject is the VERBED, because it satisfies better the unaccusative entailment than the unergative entailment.

Let us consider some verbs that are sometimes called intransitive, like break, melt, and freeze, and apply the unergative and the unaccusative entailments to them:

(5) a. The glass broke.

b. \#The glass is the breaker.

c. The broken glass

(6) a. The ice melted.

b. \#The ice is the melter.

c. The melted ice 
(7) a. The river froze.

b. \#The river is the freezer.

c. The frozen river

I am always surprised to see verbs like break, melt, and freeze characterized as intransitive. Rather than intransitive, they are detransitivized or, better yet, unaccusativized. As several scholars (Llorach, Hernanz \& Brucart, Hopper \& Thompson, La Fauci, Rosen 1988) have pointed out and this article will show, instead of referring to transitive or intransitive verbs or to the linking for a particular verb, we should be referring to transitive, intransitive, and detransitivized predicates. By the same token, it is more appropriate to talk about predicate linking than verb linking.

Let us see how the predicates in (5), (6), and (7) above are clearly related to transitive predicates.

(8) a. The heat broke the glass.

b. The heat is the breaker. (cf., \#the broken heat)

c. The broken glass (cf., \#the glass is the breaker)

(9) a. The sun melted the ice.

b. The sun is the melter. (cf., \#the melted sun)

c. The melted iced (cf., \#the ice is the melter)

(10) a. The drop in temperature froze the river.

b. The drop in temperature is the freezer. (cf., \#the frozen drop in temperature)

c. The frozen river (cf., \#the river is the freezer)

Statements like intransitive break, melt, and freeze appear to make some sense in English, since this language can detransitivize most verbs without any morphology. Many languages, however, require or strongly prefer some morphology to show that the 
40 Entailment-based Linking Theory and Some Implications for

argument in subject position is not the VERBER but the VERBED. In Spanish, the unaccusativized predicates in (11) below have reflexive (11a) or passive (11b) morphology to indicate that the argument in subject position is not the VERBER but the VERBED:

(11) a. El vaso se rompió/el hielo se derritió/el río se congeló.

"The glass itself broke/the ice itself melted/the river itself froze."

b. El vaso fue roto/el hielo fue derretido/el río fue congelado.

"The glass was/got broken/the ice was/got melted, the river was/got frozen."

c. \%El vaso rompió/el hielo derritió/el río congeló. ${ }^{3}$

"The glass broke/the ice melted/the river froze."

Reflexive morphology is also the case in other Romance languages as well as in Arabic, Croatian, Russian, German, Kannada, etc. Statements like those in (11c) are possible, but the interpretation will be a marked one. An internet search (http:// www.google.com) done on 3/22/2005 of the string "el vaso rompió" yielded 1 match (flagged as ungrammatical!) whereas "el vaso se rompió" yielded 39. The string "la puerta abrió" (the door opened) yielded 889 (some of them tokens of "...la puerta. Abrió...") whereas "la puerta se abrió" yielded 8,230.

3 The notation $\%$ means a sentence or string that is grammatical in some $\operatorname{dialect}(\mathrm{s})$ only (Huddleston \& Pullum 2002:xii). 


\section{Comparison with other Proposals}

\subsection{Dowty's Proto-agent Role and Proto-patient Roles}

According to Dowty, most linking is predictable, following the Argument Selection Principle, stated below along with Dowty's contributing properties for each protorole.

(12) Argument Selection Principle (576)

In predicates with grammatical subject and object, the argument for which the predicate entails the greatest number of Proto-Agent properties will be lexicalized as the subject of the predicate; the argument having the greatest number of Proto-Patient entailments will be lexicalized as the direct object.

(13) Contributing Properties for the Agent Proto-Role (572)

a. volitional involvement in the event or state

b. sentience (and/or perception)

c. causing an event or change of state in another participant

d. movement (relative to the position of another participant)

(e. exists independently of the event named by the verb)

(14) Contributing Properties for the Patient Proto-Role (572)

a. undergoes change of state

b. incremental theme

c. causally affected by another participant

d. stationary (relative to movement of another participant)

(e. does not exist independently of the event, or not at all)

To compare the present proposal with Dowty's, I will begin by stating the former, using the latter as a model. Thus, a first version 
42 Entailment-based Linking Theory and Some Implications for

of the Argument Selection Principle proposed here might read as follows:

(15) VERBER/VERBED Argument Selection Principle (first version)

In predicates with grammatical subject and object, the argument that satisfies the unergative entailment will be lexicalized as the subject of the predicate; the argument that satisfies the accusative entailment will be lexicalized as the direct object.

Recall that the unergative entailment selects the VERBER, and the accusative entailment selects the VERBED. We can now simplify our linking principle:

(16) VERBER/VERBED Argument Selection Principle (second version)

In predicates with grammatical subject and object, the VERBER will be lexicalized as the subject of the predicate; the VERBED will be lexicalized as the direct object.

Notice that although I am proposing to give the status of thematic role to the VERBER and VERBED of monotransitive predicates, the tests to determine verberhood or verbedhood have already been proposed in the literature (the unergative test and Bresnan's Participle-Adjective Conversion Rule).

If we compare Dowty's principle in (12) with (16), the latter is more economical. Both use two terms (proto-agent/proto-patient and VERBER/VERBED), but the VERBER/VERBED distinction does not require comparison of a set of entailments for each protorole. Thus, instead of having to count the number of entailments satisfied by a given argument, from two sets, we are dealing simply with a single unergative entailment and a single accusative entailment. Moreover, 
neither the unergative nor the accusative entailment runs into the difficulties of certain proto-agents lacking volition or sentience (as the subject argument in [17]) and certain proto-patients being unaffected (as the president in [18a]) or having volition (as the object in 17).

(17) a. Toxic waste concerns the senator.

b. The toxic waste is the concerner. (cf., \#the concerned toxic waste)

c. The concerned senator. (cf., \#the senator is the concerner)

(18) a. The visitors did not see the president.

b. The visitors are the (not) seers. (cf., \#the (not) seen visitors).

c. The (not) seen president. (cf., \#the president is the (not) seer).

In addition to these advantages, the unergative and accusative entailments are needed in the grammar of many languages to account for the two, well-known types of intransitive verbs. In fact, both Dowty's and the present proposal make this prediction. Davis claims that "Dowty's Argument Selection Principle is confined to transitive verbs, so that an important generalization cutting across transitivity is missed-namely, protorole agents are linked to subjects regardless of transitivity" (62). However, this criticism is unwarranted, because Dowty discusses the ensuing prediction that a subject of an intransitive predicate that better satisfies the protoagent entailments than the proto-patient entailments suggests that the predicate is unergative (606ff.). Likewise, a subject of an intransitive predicate that better satisfies the proto-patient entailments suggests that the predicate is unaccusative.

A characterization of intransitive predicates can follow from Dowty's Argument Selection Principle, if the linking for intransitive 
44 Entailment-based Linking Theory and Some Implications for

predicates were formulated as just sketched. As for the present proposal, when the UH is factored in, the argument selection principle predicts that for one class of intransitive predicates, the argument lexicalized as the subject will satisfy the unergative entailment, whereas for the other, the argument lexicalized as the subject will satisfy the unaccusative entailment. These entailments have already been shown in the examples with work (3) and flowers wilting (4), glass breaking, ice melting, and a river freezing (5-7).

The VERBER/VERBED Argument Selection Principle in (16) can be extended to cover intransitive predicates as follows:

(19) VERBER/VERBED Argument Selection Principle (third version)

In predicates with grammatical subject and object, the VERBER will be lexicalized as the subject of the predicate; the VERBED will be lexicalized as the direct object. An intransitive predicate is unergative if the subject is the VERBER; it is unaccusative if the subject is the VERBED.

This formulation not only captures a generalization about the unergativeness of the subject of transitive as well as a subset of intransitive predicates (the unergative ones); it also captures the accusativeness (verbedness) of the direct object of transitive predicates as well as the accusativeness of the subject of unaccusative or unaccusativized predicates.

I have already shown that the unergative entailment allows one to determine the VERBER of transitive predicates as well as the only argument of intransitive, unergative predicates. Likewise, the accusative entailment allows one to determine the VERBED of transitive predicates as well as the only argument of unaccusative or unaccusativized predicates. Before proceeding with the comparison, let us formulate a fourth and final version of the VERBER/VERBED Argument Selection Principle: 
(20) VERBER/VERBED Argument Selection Principle (final version)

The VERBER is always lexicalized as the subject. The VERBED is lexicalized as the direct object of a transitive predicate but as the subject of an unaccusative or unaccusativized one.

\subsubsection{The Linking of Psych(ological) Predicates}

Psych verbs have been a challenge for all theories of linking and for case marking (Belletti \& Rizzi 1988). Croft (1993:55) echoes familiar statements when he writes that "Variation in subject/object assignment is found both across and within a single language." On the other hand and to show just how challenging psych verbs are, Roberts (1997:93) perceives their similarities in object marking more than their subject/object variation when he writes:

This kind of property of certain Verbs is just lexical (although once again, we find that the lexica of different languages are remarkably similar in that the same semantic classes of Verbs tend to show the same inherent-Case requirements; psychological Verbs in particular very often have an inherent Dative). In fact, the link between inherent Case and Theta-roles is particularly close here: if an argument requires inherent Dative, it is almost always the Goal argument. One reason to think of this Case as inherent, then, is the fact that it is lexically determined.

Let us consider the famous pair in (21) and (22). Dowty's protorole entailments will handle (21) with ease, but he must recognize that (22) exhibits the opposite alignment of entailments (the subject is nonvolitional and nonsentient, whereas the object is volitional and sentient). The present proposal will show that the linking for psych verbs is more predictable than currently thought 
46 Entailment-based Linking Theory and Some Implications for

and that the VERBER/VERBED distinction can account for them without misalignment and other problems briefly mentioned below (22).

Consider the unergative and the unaccusative entailments as applied to these two predicates:

(21) a. John feared the article.

b. John is the fearer.

c. \#The feared John.

d. \#The article is the fearer.

e. The feared article.

(22) a. The article frightened John.

b. The article is the frightener.

c. \#The frightened article.

d. \#John is the frightener.

e. The frightened John.

As the Argument Selection Principle in (20) predicts, John is the fearer, and the article the feared, and the article is the frightener, and John is the frightener. Thus, the roles of VERBER and VERBED are aligned with the grammatical relations, and since we know that people fear articles (more generally, things and other people), but articles (things) do not fear people; and that articles frighten people but not the other way around, the sentences and entailments proposed in (21) and (22) are encountered in English and presumably in other languages. No native speaker of English utters statements like *The article feared John or *John frightened the article.

The dative marking that the nonsubject argument of predicates like those in (21) and (22) exhibit in many languages from different families is accounted for with a rule of dative overriding of the accusative, when the single object is human (González 1998). For the English examples, it suffices to realize that the VERBER/VERBED 
entailments account not only for those psych predicates in which the subject is more animate than the object, as in (21), but also for those whose object is more animate than the subject, as in (22). This linking has been done without adding any stipulation and without positing the distinction between "object of emotion" and "cause of emotion" (Pesetsky 1987; 1995) or "experiencer-subject" and "stimulus subject" (Croft 1993, Dowty 1991) and others. Incidentally, (17) and (18) offer serious challenges for the protorole entailment theory but are straightforwardly accounted for by the VERBER/ VERBED distinction, as verified by thinking about the problems that will arise for the protorole entailments theory with predicates in which the two participants are equal in animacy (18) or the object is higher in the animacy hierarchy than the subject (17).

\subsubsection{Lexical Doublets and Nonstandard Lexicalizations}

The verbs buy and sell have always been a challenge for linking theories. One problem is that the buyer and the seller are thought to participate roughly equally in the event, and therefore, proto-agent entailments are tied. Notice that this problem is more illusion than reality, for keeping the buyer and seller apart makes more sense than what appears to be implied in a nonexistent buy/sell hybrid. Notice that the inanimate object in (25) satisfies the accusative entailment, but the animate one does not. Furthermore, the unsold truck is entailed by the dealer did not sell the truck to Kim, but the unsold Kim is not, as noted by Anderson, Bresnan, Wasow, and others (Dowty 1991: 557). Let us consider (23) to (25):

(23) a. Kim bought a truck.

b. Kim is the buyer.

c. \#The bought Kim.

d. \#The truck is the buyer.

e. The bought truck. 
48 Entailment-based Linking Theory and Some Implications for

(24) a. The dealer sold two trucks.

b. The dealer is the seller.

c. \#the sold dealer.

d. \#The two trucks are the seller.

e. The sold two trucks.

(25) a. The dealer sold Kim two trucks /the dealer sold two trucks to Kim.

b. The dealer is the seller.

c. \#the sold dealer.

d. \#The two trucks are the seller.

e. The sold two trucks.

f. \#Kim is the seller.

g. \#The sold Kim.

A similar case can be made for rent and lend/borrow. Rent presents an ambiguity, but it is hardly relevant or noticeable most of the time. It is usually clear whether the renter referred to in sentences like the following intends to live in the property or to lease it to prospective tenants.

(26) a. Sara is attending WFU, and she has just rented an apartment on Reynolda Road.

b. Mr. Tower has not rented two of his six apartments this school year.

That is, both tenants and property owners are referred to as renters, but ambiguity hardly arises. University students are renters who live in apartments for a few semesters; landlords are renters who are in the business of renting to tenants for months or years. The apartments or houses are consistently the rented property. The opposite linking is not attested, because property does not rent people. Typically, banks are lenders, and customers are borrowers, 
but those are two different verbs, each with its own entailments. Thus, verbs that are troublesome for Dowty and other linking theories pose no problem for the VERBER/VERBED roles.

Yet another group of verbs is unaccounted for with protoroles. Dowty (1991:581) calls them "nonstandard lexicalizations"-for example, receive, undergo, inherit, sustain, suffer, tolerate-and although he tries to offer some hypotheses on how they might be accounted for, he admits that since they are relatively few, they can simply be treated as exceptions (581). However, those verbs need not be listed as exceptions to the VERBER/VERBED Argument Selection Principle. If we have to decide who is the VERBER and who or what is the VERBED in the following examples:

(27) a. You received a letter.

b. The pilot sustained minor injuries.

c. Uncle George suffered a heart attack.

the unergative and the accusative entailments give the following results: You are the receiver, and the letter is the received (cf., \#the letter is the receiver, \#the received you); the pilot is the sustainer, and the injuries the sustained; that is, the sustained injuries (cf., \#the injuries are the sustainer, \#the sustained pilot); Uncle George is the sufferer, and the heart attack is the suffered (cf., \#the heart attack is the sufferer, the suffered Uncle George). As these entailments show, the subject is always the VERBER, and the object is always the VERBED.

Consider, likewise, the sentences in (28):

(28) a. My brother underwent/suffered/endured an operation.

b. My brother is the undergoer/sufferer/endurer.

c. \#the operation is the undergoer/sufferer/endurer.

d. \#The undergone/suffered/endured brother.

e. The undergone/suffered/endured operation. 
50 Entailment-based Linking Theory and Some Implications for

It is not relevant that the undergoer "seems" like a patient or undergoer in the physical event of surgery. The real point is that the operation/surgery/difficulties/embarrassment, or, more generally, the change of state (physical or mental) is the undergone; that is, the VERBED, and my brother is the undergoer; that is, the VERBER. Intuitively, the subject of undergo appears to be somewhat patientlike or object-like. However, when undergoer/undergone are put together, it is easier to see that whatever the person goes through is no doubt the undergone, and whoever undergoes the undergoing is the undergoer; that is, the VERBER.

To summarize, this section has shown that the VERBER/VERBED distinction accounts for all of the facts accounted for with Dowty's protoroles. In addition, it accounts for the linking of psych verbs, doublets like buy/sell, lend/borrow, the "two" rents, and even nonstandard lexicalizations that Dowty listed as exceptions. It required no additional terms, rules, or stipulations. In this sense, this proposal is clearly more restrictive and predictive than that of Dowty.

\subsection{Wechsler's Linking Rules}

The first fully developed and, in my opinion, more constrained theory of linking in Head-Driven Phrase Structure Grammar (hereafter HPSG) is that of Wechsler, which uses three rules to account for most of the linking phenomena in monotransitive predicates in natural languages: the Notion Rule, the Nuclear Role Rule, and the Part Rule. I will briefly discuss each and compare it with the VERBER/VERBED Argument Selection Principle.

\subsubsection{The Notion Rule}

Consider the following examples (Wechsler's example 84): 
(29) a. John wants the cat.

Entails: John has a notion of the cat.

Does not entail: The cat has a notion of John.

b. John fears Mary.

Entails: John has a notion of Mary.

Does not entail: Mary has a notion of John.

Wechsler (35) claims that the concept of notion can be applied in natural language to account for the phenomenon of linking as follows:

In order to want, like, fear, or expect some individual $x$, John must have a notion of $x$, since that notion plays a role in the structure of John's mental state of wanting, liking, fearing, or expecting: it is the 'object' (content) of his wanting, etc. But it is not necessary that $x$ has a notion of John: for all we know, the cat in (48a) [our (29a)] could be unconscious. The generalization suggested by this entailment pattern is just that each sentence entails that the individual denoted by its subject NP has a notion of the individual denoted by its object $\mathrm{NP}$, while the converse entailment does not go through.

Informally stated, the Notion Rule is the claim that more cognitive participants have a notion of less cognitive participants, but that less cognitive participants need not have a notion of more cognitive ones. This rule, when applied to cognitive agents, is supported by an entailment and a non-entailment that follow from every predicate with a cognitive agent, as the examples in (29) show. In addition, it yields the expected results with verbs with a volitional agent. It accounts for the following types of verbs:

(30) a. mental state: want, like, fear, expect...

b. perception: see, hear, touch, smell... 
52 Entailment-based Linking Theory and Some Implications for

c. volitional action: murder, chase, flee... (Wechsler 40)

The Notion Rule is also consistent with many psych verbs. It is not controversial with those in which "the subject-denoted participant must be volitional," but it cannot account for verbs like terrify or astonish, which are not obligatorily volitional. Simplifying somewhat, the Notion Rule cannot account for verbs whose object is higher in the animacy hierarchy than its subject.

Consider this example from Wechsler (44):

(31) Toxic waste concerns the senator deeply.

According to the Notion Rule, the toxic waste should have a notion of the senator, but it obviously does not. Although the Nuclear Role Rule can account for many psych verbs, it cannot account for concern or preoccupy. Both verbs have to be listed as exceptions to Wechsler's linking rules.

Now, according to the VERBER/VERBED distinction, the VERBER will be lexicalized as the subject of the sentence, and the VERBED as its object. Against the widespread assumption that the linking of some psych verbs is marked (verbs like preoccupare in Italian, for example, and their corresponding verbs in many other languages), the VERBER/VERBED distinction accounts for all of them, including concern and preoccupy, astonish and terrify, and also those for which Wechsler claims the Notion Rule fails to account and consequently applies the Nuclear Role Rule. If one looks at the sentence in (31) and asks who or what the concerned is, the answer is the senator. Of course, the toxic waste is the concerner (cf. \#the concerned toxic waste). The reader can review the entailments for a similar predicate in (17). The VERBER/VERBED distinction also accounts for preoccupy. The reader can verify it by replacing concern with preoccupy (and also worry) in (31).

Consider again (21) and (22), repeated below as (32), a very 
troublesome pair for all linking theories and repeated here, because Wechsler offers a solution different from that offered by Dowty.

(32) a. John feared the article.

b. The article frightened John.

Wechsler's Notion Rule accounts for (32a), since John would have a notion of the article. One possible problem is that notion seems to imply volition-Wechsler states that "the subject denoted participant must be volitional" (40) - and if so, it is somewhat hard to accept that people engage willfully in acts of fearing. (32b) cannot be accounted for with the Notion Rule; it will have to be accounted for with the Nuclear Role Rule, which I will discuss in the next section.

As the following section will show, the Nuclear Role Rule amounts to a stipulation not needed with the VERBER/VERBED distinction. As seen in (21) and (22), John is the fearer (VERBER), and the article is the feared (VERBED). In the other sentence, the article is the frightener, and John is the frightened. I claim that this information is all that any speaker or listener needs to encode (or to arrive at) the right interpretation for predicates like these.

\subsubsection{The Nuclear Role Rule}

This rule accounts for the linking of many verbs that involve a nonvolitional agent and therefore cannot be explained with the Notion Rule. It is supposed to explain predicates like the following, all of them from Wechsler (47).

(33) a. The virus infected the organism.

b. The acid dissolved the metal.

c. The sponge absorbed the water.

d. The fire killed seven people. 
54 Entailment-based Linking Theory and Some Implications for

e. The sun melted the ice cubes.

The explanation rests on the assumption that one of the participants is nuclear, and the nuclear participant is cast as the object of the sentence. Wechsler (50) defines nuclear roles as follows:

...roles for which a change of state in the participant filling them lends the denoted event its temporal constitution will be called nuclear roles, reflecting the fact that they are part of the aspectual 'nucleus' of the event.

It is not clear to me what "lends the denoted event its temporal constitution" means. It seems to mean that the "nuclear" participant is more affected than the other participant. Indeed, Wechsler (48) favors the view that the effect is more prominent than the cause; hence, the participant who is more affected is marked as [+nuclear] and cast as the object. It is generally true that the participant who is more affected or who undergoes a more noticeable change of state is cast as the object of the sentence, but some scholars might have problems with the claim that the water in (33c) changes state or is more affected than the sponge. It certainly changes location, but on the account of affectedness, changing location seems a less drastic change of state than becoming wet, for example.

The VERBER/VERBED distinction accounts for all the sentences discussed by Wechsler without need for the troublesome Nuclear Role Rule. It also accounts for sentence (33c), for which the Nuclear Role Rule might have to be modified to include change of location. Anyone who has done work on thematic roles will know that such a move would most probably create more problems than it would solve. Indeed, since one of the participants has to be more affected than the other for the participant to be marked as nuclear, the Nuclear Role Rule cannot account satisfactorily for sentences like 
(34) This device monitors the patient's heartbeat (example [93], 57).

A sentence like (34) is problematic, because the patient's heartbeat causes the monitoring, and it should be cast as the subject of the sentence (in the Nuclear Role Rule, the cause is cast as the subject, and the effect is cast as the object; see 48). In this case, the patient's heartbeat is not the effect, nor is the monitoring device a cause. The VERBER/VERBED distinction accounts for this example straightforwardly: The monitored is the patient's heartbeat, and the "monitorer" (that is, the monitor) is the device.

The Nuclear Role Rule cannot account for sentences like those in (35), either.

(35) a. Some hailstones hit the car.

b. The car hit some hailstones.

c. The cold buckle touched the skin.

d. The skin touched the cold buckle.

Although it predicts the correct linking in (35b) due to the fact that, under most circumstances, the hailstones will be more affected than the car, it cannot predict the linking for (35a), since the car has to be more affected. By the same token, the skin will be more affected than the buckle, since we can probably see a more noticeable disturbance-a shiver, goosebumps-on it than on the buckle. The Nuclear Role Rule will predict the linking for (35c) but not for $(35 \mathrm{~d})$.

The VERBER/VERBED distinction easily accounts for sentences like those in (35) without the need to mark one participant as [+nuclear] or assuming a change of state, which is negligible and completely irrelevant for all practical purposes for (35c) and nonexistent for (35d). In my opinion, the Nuclear Role Rule does not account for examples like The sponge absorbed the water or The 
56 Entailment-based Linking Theory and Some Implications for

skin touched the buckle.

Once again, the VERBER/VERBED distinction provides all the information that is needed to encode or process the meaning intended: speakers of English can readily identify the water as the absorbed and not the other way around. The VERBED will pick up the buckle or the skin as the touched, depending on what touches what. Incidentally, since water does not seem to absorb sponges, the VERBER/VERBED distinction appears to predict the unlikelihood of sentences like

(36) \#The water absorbed the sponge.

\subsubsection{The Part Rule}

Informally stated, the Part Rule says that the whole is cast as the subject, and the part is the object. This rule includes "container" verbs (contain, include) as in (37a) below, as well as verbs like dominate, constitute, form, subsume, extend, involve, support, entail, presuppose, imply, implicate, suggests (all examples from Wechsler, $58,59,61)$.

(37) a. This toothpaste contains sugar.

b. The VP dominates the NP.

c. This fact entails/presupposes/implies/implicates/suggests John's claim.

Wechsler (59) claims that there are no verbs exhibiting the reverse pattern; that is, no whole is cast as the object. Davis (110) concurs with Wechsler and sees the need to posit a whole-partrelation. However, the next section will show that the Part Rule makes some incorrect predictions that the VERBER/VERBED distinction does not and also fails to predict the linking of some verbs that the VERBER/VERBED distinction can predict. 


\subsection{4. "Syncategorematic" Verbs}

Previous accounts of linking have not been able to explain some verbs. Wechsler calls them "semantically syncategorematic" predicates. Dowty calls them symmetric predicates. Consider the following examples ([38a] is from Wechsler [61], but the other examples are mine):

(38) a. The U.S. comprises fifty states.

b. Fifty states comprise the U.S.

c. Oxygen and hydrogen make up water.

d. *Water makes up oxygen and hydrogen.

e. * Oxygen and hydrogen are made up of water.

At first sight, (38a,b) seem to be syncategorematic; that is, the two roles appear to be identical, and it would not be possible, in principle, to always assign one of them to the subject and the other to the object, since they should be interchangeable. According to Wechsler (61), neither the Notion Rule, the Nuclear Role Rule, nor the Part Rule can account for these examples.

It turns out that the Part Rule would predict that the sentence in (38d) is grammatical (the whole is cast as the subject); yet it is ungrammatical. On the other hand, the VERBER/VERBED does predict precisely that (38d) is ungrammatical, since the oxygen and the hydrogen are not the "made ups" (39e). The following sentence proves that the water is the "made up"; that is, the VERBED:

(39) Water is made up of oxygen and hydrogen.

By virtue of the fact that water is the subject of a passive sentence, we know with absolute certainty that it is the object of the active sentence. Thus, the present theory predicts the ungrammaticality of sentence (38d) and also predicts the correct linking of sentence 
58 Entailment-based Linking Theory and Some Implications for

(38c), which the Part Rule would predict to be (38d), a wrong prediction, since the sentence is ungrammatical.

Sentences (38a) and (38b) seem completely "syncategorematic" in modern English.

Consider the data in (40) and (41).

(40) a. The U.S. is comprised of fifty states.

b. *Fifty states are comprised of the U.S.

(41) Fifty states comprise the U.S.

The fact that the passive in (40a) is possible but not the one in (40b) is evidence that the "basic" linking is which is clearly correct: The US is comprised of fifty states, but Fifty states are not comprised of the US. Once again, the ungrammaticality of (40b) is predicted by the VERBER/VERBED distinction, and the Part Rule would predict that the linking is as in (42) because the whole is mapped as the subject.

(42) The U.S. comprises fifty states.

However, that mapping yields an ungrammatical sentence when it is rendered in the passive (40b).

Thus, at least two verbs do not cast the whole as the subject and are clear exceptions to the Part Rule, yet the VERBED/VERBER distinction accounts for them. See in (43) other examples of comprise and make up, which are accompanied by a passive paraphrase that shows that the subject is the object of the active voice sentence:

(43) a. Five chapters comprise the book.

b. The book is comprised of five chapters. (cf., \#Five chapters are comprised of the book). 
c. Constituents make up wholes.

d. Wholes are made up of constituents. (cf., \#Constituents are made up of wholes)

e. A string of sounds makes up a word.

f. A word is made up of a string of sounds. (cf., \#A string of sounds is made up of a word).

I have also found at least one other verb (compose) that cannot be accounted for with the Part Rule. Below, (44) is the corresponding active voice sentence, slightly modified, of "the clause is a syntactic unit composed of the core and periphery" (Van Valin and LaPolla 29). I take (45) from Granger (163).

(44) a. The core and the periphery compose the clause.

b. The core and the periphery are the composers.

c. \#The composed core and periphery.

d. \#The clause is the composer.

e. The composed clause.

(45) a. The parts (that) compose the whole.

b. The parts are the composers.

c. \#the composed parts.

d. \#The whole is the composer.

e. The composed whole.

In short, the Part Rule is neither without exception nor does it predict the correct linking of several predicates whose linking is correctly predicted by the VERBER/VERBED distinction.

\section{Implications for Universal Language}

Linking (the matching of grammatical relations with thematic 
60 Entailment-based Linking Theory and Some Implications for

roles) is a foundational issue for any linguistic theory. This article is part of a research program that shows a more restrictive and predictive theory of linking. It is restrictive because instead of computing a set of entailments to determine agenthood or patienthood, the learner has to apply two discrete entailments: the VERBER test or the VERBED test. It is also restrictive because it shows that it can accomplish with the same two discrete entailments what the three rules in Wechsler's theory do.

The present proposal is predictive because it explains data unaccounted for (lexical doublets, nonstandard lexicalizations, syncategorematic verbs), and it does so without any change, addition, or modification to the VERBER/VERBED Argument Selection Principle. The present proposal can even account for one class of verbs (verbs whose object is more animate than the subject) unaccounted for in Wechsler's theory. The fact that this proposal account for data unaccounted for in two different theories is evidence that it is on the right track. I concentrated on English for brevity, and because, to the best of my knowledge, the main linking theories have been proposed first in English. Interestingly, the same analysis obtains in Spanish, a language belonging to a different family. Two languages are not enough to claim universality, but the simplicity and the predictability of the present analysis indicates that it should be empirically tested in other languages. Presumably, an artificial language will have to avail itself of a linking theory, since linking theory is an essential part of any human language. It is also natural to assume that an artificial language will consider whether it can model its own linking theory on an existing one in natural language.

The Unaccusative Hypothesis (UH) is perhaps the only concept in linguistics shared by all current linguistic theories. The present proposal is consistent with it. In fact, unaccusativity can be easily understood using the present framework. There are two classes of intransitive predicates: unergatives and unaccusatives. An unergative predicate is a predicate whose only argument is a VERBER; an 
unaccusative predicate is a predicate whose only argument is a VERBED. This characterization of unaccusativity has enough merits to have the present proposal empirically tested in different languages. If it works, it will be a significant contribution to universal language; if it does not, it will show where to search for a better theory of linking.

As the discussion of verbs like wilt as opposed to break, freeze, melt begins to show, the number of truly intransitive unaccusative verbs is relatively small. However, many transitive verbs can unaccusativize, i.e., omit its VERBER and cast its VERBED as the subject. Languages with a rich reflexive morphology signal VERBER omission by deploying a reflexive pronoun, as example (11) shows. If a learner of Spanish as a second language (and presumably other languages with a rich reflexive morphology) can determine that the participant showing up in subject position is the VERBED, not the VERBER, that learner can be almost sure that s/he needs to use a reflexive pronoun to indicate VERBER omission. To my knowledge, this rule has not been proposed. It should, however, be part of pedagogical grammars. It should also be part of any grammar, but native speakers can use reflexive pronouns without the need for explicit rules.

\section{Conclusions}

In summary, the VERBER/VERBED Argument Selection Principle in (20) accounts for all the linking that Dowty's protoroles and Wechsler's Notion Rule, Nuclear Role Rule, and Part Rule account for, without the need for two sets of proto-entailments and the three rules. Furthermore, it accounts for predicates whose object is higher in the animacy hierarchy than their subject (concern, frighten, preoccupy, worry, etc.), for predicates whose subjects and objects are equal in the animacy hierarchy, and for several other exceptions 
62 Entailment-based Linking Theory and Some Implications for

in Dowty.

\section{References}

Alarcos, E. 1978. Estudios de Gramática Funcional del Español. Madrid: Gredos.

Anderson, S. 1977. Comments on the Paper by Wasow. In P. Culicover, T. Wasow, \& A. Akmejian, 361-368.

Belletti, A. \& L. Rizzi. 1988. Psych-verbs and $\theta$-theory. Natural Language and Linguistic Theory 6, 291-352.

Bresnan, J. 1982. The Passive in Lexical Theory. In J. Brensan (ed.), The Mental Representation of Grammatical Relations 3-86. Cambridge, MA: MIT Press.

Carlson, G. 1984. Thematic Roles and their Role in Semantic Interpretation. Linguistics 22, 259-279.

Croft, W. 1993. Case Marking and the Semantics of Mental Verbs. In J. Pustejovsky (ed.), Semantics and the Lexicon 55-72. Dordrecht: Kluwer.

Culicover, P., T. Wasow, \& A. Akmejian. 1977. Formal Syntax. New York: Academic Press.

Davis, A. 2001. Linking by Types in the Hierarchical Lexicon. Stanford, CA: CSLI Publications.

Dowty, D. 1991. Thematic Proto-roles and Argument Selection. Language 67, 547-619.

Farrell, P. 1994. Grammatical Relations and Thematic Roles. New York: Garland.

González, L. 1998. Dative/Accusative Alternations in Gustar-type Verbs. Spanish Applied Linguistics 2.2, 137-167.

Granger, S. 1983. The be+past Participle Construction in Spoken English: With Special Emphasis on the Passive. Amsterdam: North-Holland.

Gruber, J. 1976. Lexical Structures in Syntax and Semantics. Amsterdam: North-Holland Publishing Company.

Hernanz, M. \& J. Brucart. 1987. La Sintaxis I. Principios Generales. La Oración Simple. Barcelona: Crítica.

Hopper, P. \& S. Thompson. 1980. Transitivity in Grammar and Discourse. Language 56, 251-99. 
Huddleston, R. \& G. Pullum. 2002. The Cambridge Grammar of the English Language. Cambridge: Cambridge University Press.

Ladusaw, W. \& D. Dowty. 1988. Toward a Nongrammatical Account of Thematic Roles. In W. Wilkins (ed.), 62-73.

La Fauci, N. 1988/1994. Objects and Subjects in the Formation of Romance Morphosyntax. Translated by C. Rosen. Bloomington, IN: Indiana University Linguistics Club Publications.

Legendre, G. 1989. Unaccusativity in French. Lingua 79, 95-164.

Levin, B. \& M. Hovav. 1995/1999. Unaccusativity. At the Syntax-lexical Semantics Interface. Cambridge, MA: MIT Press.

Perlmutter, D. 1978. Impersonal Passives and the Unaccusative Hypothesis. Berkeley Linguistics Society 4, 177-189.

Pesetsky, D. 1987. Binding Problems with Experiencer Verbs. Linguistic Inquiry 18, 126-40. MA: MIT Press.

Pollard, C. \& I. Sag. 1994. Head-driven Phrase Structure Grammar. Chicago, IL: University of Chicago Press.

Rappaport, M. \& B. Levin. 1988. What to Do with Theta-roles. In W. Wilkins (ed.), 7-36.

Roberts, I. 1997. Comparative Sntax. London: Arnold.

Rosen, C. 1988. The Relational Structure of Reflexive Clauses: Evidence from Italian. New York: Garland.

Van Valin, R. \& R. LaPolla. 1997. Syntax. Structure, Meaning, and Function. Cambridge: Cambridge University Press.

Wasow, T. 1977. Transformations and the Lexicon. In P. Culicover, T. Wasow, \& A. Akmejian, 327-360.

Wechsler, S. 1995. The Semantic Basis of Argument Structure. Stanford, CA: CSLI Publications.

Wilkins, W. (ed.). 1988. Syntax and Semantics 21: Thematic Relations. San Diego, CA: Academic Press. 